\title{
Simultaneous presence of excess weight and insufficient hours of sleep in adolescents: prevalence and related factors
}

Open acess

${ }^{1}$ Federal University of Santa Catarina. Sports Center.

${ }^{2}$ Research Center in Kinanthropometry and Human Performance.

Florianopolis, Santa Catarina, Brazil.

\section{Corresponding author:}

tiagopersonaltrainer@gmail.com

Manuscript received: 11 June 2017 Manuscript accepted: 02 July 2017 Version of record online: 06 September 2017
Tiago Rodrigues de Lima1', Gabriel Renaldo de Sousa1, João Antônio Chula de Castro ${ }^{2}$, Diego Augusto Santos Silva ${ }^{12}$

\begin{abstract}
Introduction: An increase in excess body fat and a decrease in the number of hours of sleep per day are health problems affecting the paediatric population.

Objective: To estimate the combined prevalence of overweight and insufficient sleep/day in adolescents, and the association with sociodemographic characteristics, physical activity and sedentary behaviour.

Methods: A cross-sectional school-based study was conducted with 1,132 participants from 14 to 19 years old in São José, Santa Catarina, Brazil. Body fat was assessed by body mass index (BMI) and classified by the Z-score, while adolescents reported the total hours of sleep/day. Sociodemographic data, physical activity and sedentary behaviour were collected by self-filled questionnaire.
\end{abstract}

Results: The simultaneous prevalence of overweight and insufficient sleep/day was $17.5 \%$. The factors associated with this condition were to meet the recommendations of the practice of physical activity per week, participate in gym class twice/week and period greater/equal to four hours/day in front of the screen.

Conclusion: Guidelines in the school environment in relation to health problems posed by weight excess and the amount of insufficient hours sleep can be present when recommendations on physical activity and sedentary behaviour are given to students.

Keywords: obesity, overweight, body mass index, epidemiology, adolescent health, motor activity, crosssectional studies 


\section{INTRODUCTION}

The increase in excess body fat is one of the major public health problems ${ }^{1}$. By 2013, more than 40 million children worldwide had an excessive accumulation of body fat1. In Brazil, in the period 2008-2009, the Family Budget Survey (POF) estimated a prevalence of overweight and obesity for the age group of 10 to 19 years of age as $21.7 \%$ and $5.1 \%$ for boys, and $19.4 \%$ and $4.0 \%$ for girls, respectively ${ }^{2}$. The subgroups of adolescents with higher frequencies of overweight/obesity were boys, students of the public school system, who had low economic status and lower maternal schooling ${ }^{3,4}$.

The energy imbalance in relation to the amount of calories consumed and spent is a risk factor for excess body fat ${ }^{1}$. Another factor directly associated with this condition in adolescents is the increase in the intake of foods rich in empty calories and fat ${ }^{1}$. Among the consequences of excess body fat in adolescents, there is an evidence of increased insulin resistance, increased blood pressure and dyslipidaemia, which are risk factors for cardiometabolic diseases ${ }^{5}$.

The decrease in the number of hours of sleep/day is another epidemic that affects the paediatric population ${ }^{6}$. The National Sleep Foundation recommends a period equal to or greater than eight hours of sleep per day for children and adolescents ${ }^{7}$. The study by Matricciani et al. ${ }^{8}$ identified, through an evaluation of studies dating from 1905 to 2008, a secular tendency to decrease the number of hours of sleep in children and adolescents. In Brazil, a survey conducted with adolescents identified an increase of $45.9 \%$ in the number of hours of sleep ( $<8$ hours per day) during the period from 2001 to $2011^{9}$. The students who had an insufficient number of hours of sleep/day were male adolescents with a high economic level and high maternal education ${ }^{6,9-11}$.

Social and recreational lives, early school hours, academic tasks, school and work-related demands, and biological factors such as changes in the sleep-wake cycle that occur during adolescence are causal aspects of insufficient hours of sleep/day ${ }^{9}$. Excessive daytime sleepiness,

\section{METHODS}

\section{Population and sample size}

A This cross-sectional, epidemiological, schoolbased research is linked to the project 'Brazilian Guide for the Assessment of Physical Fitness Related to Health and Life Habits - Stage 1'. This study was carried out in the city of São José, Santa Catarina, in the southern region of Brazil. The municipality has a Human Development Index of 0.809 , with a life expectancy at birth of 77.81 years, a per capita income of $\mathrm{R} \$ 1,157.43$ and GINI index of $0.44^{16}$.

The study population consisted of 5,182 highschool students from public schools in the city of São José, distributed in 11 eligible schools and 170 highschool classes.

The sampling process was determined in two steps: the first was stratification of the school density (size: small, with less than 200 students; average, with 200 to 499 students; and large, with 500 students or more). In the increased body mass, decreased glucose tolerance, and decreased insulin sensitivity are some of the complications associated with decreased hours of sleep/day ${ }^{12,13}$. Another factor associated with the insufficient number of hours of sleep in adolescents was the large number of hours spent in front of a screen ${ }^{10}$.

A study carried out with European adolescents found that schoolchildren who performed the least amount of physical activity had excess body fat and slept the least number of hours $/$ day ${ }^{10}$. Being awake for too long leads to fatigue ${ }^{10}$ and this fatigue can directly contribute to reduced levels of physical activity, and the lower energy expenditure resulting from this condition may result in excess body fat ${ }^{10}$. However, another study emphasized the opposite, in that decreasing the number of hours of sleep/day resulted in increased ghrelin levels and decreased leptin concentration, leading to increased appetite and calorie intake, increasing the chances of having excess body fat ${ }^{12}$.

There are several recommendations aimed at reducing body fat in overweight/obese adolescents, such as restriction of caloric intake, increased consumption of healthy foods, increased hours of sleep, greater engagement in physical activity and decrease in sedentary activities $^{1,12,14}$

In view of the risks associated with excess body fat and insufficient number of hours of sleep per day in adolescents and their bi-directional causalities, working with both conditions becomes relevant.

Thus, the present study differs from other studies $^{3,7-9,12,13,15}$ because it investigated the sociodemographic factors, physical activity domains and sedentary behaviour associated with the combination of excess body fat and insufficient hours of sleep/day, since identifying the subgroups of adolescents most susceptible to such simultaneity is important for the elaboration and effectiveness of coping strategies. In this way, the objective is to analyse the factors associated with excess body fat and insufficient sleep/day combined in adolescents.

second step, the time of study and the teaching series were considered.

To estimate the sample size, the prevalence was unknown for the outcome $(50 \%)$, a tolerable error of five percentage points, a 95\% confidence level, a delineation effect of 1.5 , and $20 \%$ was added for losses and refusals plus $20 \%$ to control the possible confounding variables. In this way, it would be necessary to evaluate 751 adolescents. Due to the conglomerate sampling, all the students in the classes were invited to participate in the survey, and thus, a sample of 1,132 students had their data collected. Of these, 1,119 students answered questions related to the number of hours of sleep/day and were analysed in relation to body mass and height, necessary for determination of their body mass index (BMI).

The data used in this study come from the aforementioned research, in which the calculation of sample 
size considered the associations of interest of the research that demanded the largest numbers of respondents. Since the present study used data to examine issues other than the broader survey, we calculated the statistical power available to assess the combination of sleep/day hours and body fat with all variables of interest. Statistical power is the probability of not rejecting a false null hypothesis, that is, declaring that there is no difference when it actually exists, in which values from $80 \%$ are considered adequate to avoid such error ${ }^{17}$. In the present study, the combination of body fat excess and insufficient number of hours of sleep/day and the variables gender (which obtained power of $8.0 \%$ ), school displacement (15.2\%) and TV time $(10.2 \%)$ were those with the lowest statistical power for association tests.

Data collection took place in the school environment in the second half of 2014, during the months of August to November. The work team was made up of undergraduate and graduate students in physical education, previously familiar with and trained to apply the questionnaire and physical assessments. The project questionnaire was applied in the classroom, and the data was selffilled by the students.

\section{Dependent variable}

Number of hours of sleep/day and body fat: sleep data were obtained based on a structured questionnaire, using the question 'What is your bedtime and wake up time?' This item was divided in relation to the weekly periods, from Monday to Thursday; Friday to Saturday; Saturday to Sunday; and Sunday to Monday, with response options regarding bedtime and waking hours. To define the number of average hours of sleep of the students, the average of these results was realized, in which the number of hours of sleep verified from Monday to Thursday was multiplied by four, and the values verified from Friday to Saturday, Saturday to Sunday and Sunday to Monday were summed and the total was divided by seven (number of days of the week) ${ }^{10}$. The result was later categorized into $<$ eight hours of sleep/day and $\geq$ eight hours of sleep/day, according to the National Sleep Foundation $^{7}$. Body fat was verified using BMI, which uses body mass and height to identify the nutritional status of the individual. The height was collected through a stadiometer with a Sanny ${ }^{\circledR}$ brand tripod (São Paulo, Brazil) and the G-tech ${ }^{\circledR}$ digital scale body mass (Zhongshan, China). The BMI was calculated from the formula: BMI = body mass/stature ${ }^{2}$. In order to classify the results in relation to BMI, we used the Z-score cut-off points proposed by the World Health Organization ${ }^{18}$, in which the definition of overweight is $>+1$ standard deviation, and obesity is $>+2$ standard deviations. In the present study, students classified above $>1$ standard deviation were considered as having excess body fat and those below this classification, without excess body fat ${ }^{18}$.

Based on these data, four distinct groups were constituted: 1) hours of sleep $\geq$ eight hours/day and without excess body fat; 2) hours of sleep $\geq$ eight hours/day and with excess body fat; 3 ) hours of sleep < eight hours/ day and without excess body fat; 4) hours of sleep $<$ eight hours/day and with excess body fat.

\section{Independent variables}

The sociodemographic variables were age in complete years (categorized in 14/15 years, 16/17 years and $18 / 19$ years). This variable was categorized in this way due to divergent cognitive and social changes between students entering high school (from 14/15 years of age), those who are at the appropriate age (16/17 years old) and the other students, who have already surpassed 18 years old and should have completed high school; (Categorized in up to eight years of study and eight years or more of study), in order to match the average years of study of Brazilian adults $(7,8 \text { years })^{19}$; Family income was collected, according to the Brazilian Institute of Geography and Statistics $^{20}$, as the number of minimum wages received among family members (minimum wage equivalent to $\mathrm{R} \$ 724.00$ in the data collection period), categorized into up to two minimum wages (low) / two to ten minimum wages (average) / above ten minimum wages (high).

The variables global physical activity, physical activity in leisure and sports team participation were evaluated by the Brazilian version of the Youth Risk Behaviour Surveillance (YRBSS) questionnaire, used in the United States, translated and validated for Brazil ${ }^{20}$. This questionnaire presented a moderately high kappa concordance index, with an average of $68.3 \%$ and a median of $68.5 \%{ }^{21}$.

The level of overall physical activity was collected by the question "During the past seven days, on how many days were you physically active for at least 60 minutes a day?" This questioning had the dichotomized responses in not meeting the recommendations (zero to four days) and meeting the recommendations (five days or more), because studies describe that physical activity performed for at least five days of the week, for at least 60 minutes, brings health benefits to adolescents ${ }^{22}$.

The responses to this questioning were dichotomized into active activities (physical activities, sports and dances) and passive activities (playing cards, dominoes, snooker, watching TV, using computer, cultural and manual activities). This categorization was adopted as active physical activities generate greater energy expenditure and mobilization of body mass in relation to sedentary ones $^{22}$.

Participation in the sports team was verified by the question 'During the last 12 months, have you played on any sports teams?'. The answer was categorized as 'no' (no team) and 'yes' (one or more teams), since engagement in sports practices generates improvement in the skeletal musculature and increase in muscular mass, which can help in the maintenance of the body mass ${ }^{22}$.

The variables related to the number of physical education classes and school dislocation are from the Santa Catarina Adolescent Behaviour (COMPAC) questionnaire whose r-values for the independent items and grouped by thematic unit ranged from 0.64 to 0.994 . The number of physical education classes was collected by the question 'During a typical week, in how many physical education classes do you participate?' The answers to this item were classified into one class per week; two classes per week; and three or more classes per week, since a greater number of sessions of physical activities leads to greater energy expenditure and metabolic alterations that can directly in- 
fluence body fat and sleep hours ${ }^{1,11,22}$.

The displacement to school was verified by the question 'How do you usually get to school?' The answers to this question were dichotomized into passive displacement (car, motorcycle and bus); and active displacement (walking and cycling). The classification of this variable for the analysis was due to the greater energy demand to perform active displacement in relation to the liability ${ }^{22}$.

The time spent watching TV, using the computer (PC) and video games (VGs), was collected through six questions regarding the number of hours and minutes the equipment was used during the periods from Monday to Friday and weekends. For the definition of TV, PC and total VG time, the sum of the number of hours during the week and the weekends was divided by the seven days of the week. These variables were later categorized into $<$ two hours/day and $\geq$ two hours/day as recommended in the literature ${ }^{14}$.

For the total screen time variable, we used the sum of the time spent on TV, PC and VGs during a week divided by seven, after which the response was dichotomized in time less than four hours/day of screen time and greater time or equal to four hours/day of screen time, due to the direct association with the increased risk of cardiovascular diseases and all-cause mortality ${ }^{23}$. Similar questions addressing the time of screen use were used in international studies $^{14}$, with good reliability and reproducibility in Brazilian adolescents $(\mathrm{CI}=0.76$; 95\% CI: 0.70-0.81; kappa $=0.52)^{24}$.

\section{Control variables}

Sexual maturation was self-rated by adolescents using maturational development boards proposed by Marshall and Tanner ${ }^{25}$, elaborated by the Department of Nutrition of the Federal University of Santa Catarina, Santa Catarina, Brazil, where the result of the Kendall correlation coefficient was 0.627 ( $p<0.01$ ) for boys and 0.739 ( $p$ $<0.01$ ) for girls ${ }^{26}$. These boards contained photographs of the five stages of maturational development, with the adolescent being asked to look closely at each photograph and to mark in the questionnaire what most resembled their genital organ size for boys and breast size for girls. The development stage of the genitalia (G1, G2, G3, G4, G5) was considered for the male gender and the development of the breasts' (M1, M2, M3, M4, M5) characteristics and shape. Stage 1 corresponded to prepubertal growth and development, while stages 2 to 4 corresponded to puberty progression to full maturation (stage 5). Same sex evaluators explained the objective and importance of this evaluation and individually oriented the students'.

\section{RESULTS}

It was found that more than half of the sample consisted of girls $(54.2 \%)$. The majority of the population were 16-17 years old, from families with an income of two to ten minimum wages $(68.3 \%)$ and whose mothers hadup to eight years of schooling $(56.2 \%)$. It was also found that more than three-quarters of the schoolchildren did not meet the recommendations for weekly physical activity (77.2\%) and a large proportion of these students
Information on the quality of sleep was collected through the following question: 'Do you sleep well and feel rested?' And the answers to this questioning were classified as 'no' (infrequently, rarely and sometimes) and 'yes' (relatively often and often). The perception of sleep quality was used as a control variable because it was directly associated with the number of hours of sleep ${ }^{9}$.

\section{Statistical analysis}

The chi-square test with Rao-Scott correction was used to analyse the association between the characteristics of overweight/obese students and total hours of sleep. Subsequently, these associations were evaluated in the context of multinomial logistic regression models, with odds ratios estimation and $95 \%$ confidence intervals $(95 \% \mathrm{CI})$. The sleep hours category $\geq 8$ hours/day and no excess body fat was considered as a reference. The sociodemographic and behavioural variables of adolescents were analysed as possible effect modifiers, considering in this case a $p$ value $<0.10$ as indicative of interaction ${ }^{27}$.

In the adjusted analysis all variables were inserted at the same level, regardless of the $p$ value in the crude analysis, those with a $p$ value $\leq 0.20$ and the use of the backward method remaining in the model. Sexual maturation and sleep quality were maintained in the independent $\mathrm{p}$ value model, since they were used as control variables. All analyses were corrected by the effect of the study design and sampling plan using the svy command. The strategy initially adopted for the statistical modelling of data was the construction of a saturated model (with the dependent variable and interaction among all the independent ones), but the fact that the parameters were not estimated made it impossible to maintain this proposal. Thus, a sub-saturated model was constructed (according to the software's maximum capacity). and checking parameters such as R2, Akaike's Information Criterion (AIC), and Bayesian Information Criterion (BIC). performed the adjustment of the regression model. Statistical analysis was performed in the Stata Statistical Software for Professionals, Texas, version 13.0.

\section{Ethical aspects}

This study was approved by the Ethics and Research Committee with Human Beings of the Federal University of Santa Catarina under the CAEE protocol: 33210414.3.0000.0121. Only those subjects who returned the informed consent form signed by their parents ( $<18$ years) or by themselves ( $\geq 18$ years old), together with the consent form signed by the adolescent, participated in the study.

performed sedentary activities during their leisure period $(56.1 \%)$. Approximately $70.0 \%$ of the schoolchildren participated in two physical education classes per week, half $(50.7 \%)$ participated in sports teams outside school hours and just over half (52.1\%) used passive transportation (car, motorcycle, bus) to go to school. Regarding TV time, just over half watched for a period of more than two hours a day, $54.8 \%$ used a PC for more than two hours a 
day and $15.4 \%$ played VGs more than two hours a day. Regarding the daily time in front of the screen (TV $+\mathrm{PC}+$ $\mathrm{VG}$ ), approximately two-thirds of the sample spent a time that was greater/equal to four hours (64.2\%). Furthermore, it was found that approximately half of the students slept less than eight hours/day and $34.4 \%$ had excess body fat (Table 1).

Table 1: Distribution of schoolchildren from state public schools in São José, SC, Brazil, 2014

\begin{tabular}{|c|c|c|}
\hline Variables & $\mathbf{n}$ & $\%(\mathrm{Cl} 195 \%)$ \\
\hline \multicolumn{3}{|l|}{ Sex } \\
\hline Male & 519 & $45,8(36,0-56,0)$ \\
\hline Female & 613 & $54,2(44,0-64,0)$ \\
\hline \multicolumn{3}{|l|}{ Age (years) } \\
\hline $14-15$ & 361 & $31,8(30,3-33,2)$ \\
\hline $16-17$ & 649 & $57,4(55,1-59,6)$ \\
\hline $18-19$ & 122 & $10,8(9,0-13,0)$ \\
\hline \multicolumn{3}{|l|}{ Monthly Family Income (minimum wages)a } \\
\hline Up to two wages & 253 & $26,9(19,7-35,6)$ \\
\hline Two to ten wages & 639 & $68,3(65,0-71,5)$ \\
\hline Above ten wages & 44 & $4,8(1,7-12,4)$ \\
\hline \multicolumn{3}{|l|}{ Maternal Education } \\
\hline $0-8$ years & 631 & $56,2(41,7-69,7)$ \\
\hline $9-11$ years & 487 & $43,8(30,3-58,3)$ \\
\hline \multicolumn{3}{|l|}{ Global physical activity ${ }^{\mathrm{b}}$} \\
\hline Does not heed the recommendations & 851 & $77,2(73,4-80,6)$ \\
\hline Meets recommendations & 252 & $22,8(19,4-26,6)$ \\
\hline \multicolumn{3}{|l|}{ Physical activity at leisure } \\
\hline Sedentary & 604 & $56,1(53,3-59,0)$ \\
\hline Active & 476 & $43,8(41,0-46,7)$ \\
\hline \multicolumn{3}{|l|}{ Number of Physical Education classes } \\
\hline One class per week & 201 & $19,6(15,5-24,5)$ \\
\hline Two lessons per week & 747 & $71,2(62,3-78,9)$ \\
\hline Three or more lessons per week & 95 & $9,2(5,1-15,8)$ \\
\hline \multicolumn{3}{|l|}{ Participation in sports team } \\
\hline No & 542 & $49,3(33,9-64,9)$ \\
\hline Yes & 565 & $50,7(35,1-66,1)$ \\
\hline \multicolumn{3}{|l|}{ Displacement to school ${ }^{\circ}$} \\
\hline Passive & 569 & $52,1(39,7-63,7)$ \\
\hline Active & 536 & $47,9(33,4-59,2)$ \\
\hline \multicolumn{3}{|l|}{ TV time } \\
\hline$<2$ hours per day & 548 & $48,8(45,6-51,9)$ \\
\hline$\geq 2$ hours per day & 570 & $51,2(48,0-54,3)$ \\
\hline \multicolumn{3}{|l|}{ PC Time } \\
\hline$<2$ hours per day & 502 & $45,2(40,1-50,3)$ \\
\hline$\geq 2$ hours per day & 612 & $54,8(49,6-59,8)$ \\
\hline \multicolumn{3}{|l|}{ VG time } \\
\hline$<2$ hours per day & 946 & $84,6(74,6-91,1)$ \\
\hline$\geq 2$ hours per day & 172 & $15,4(8,9-25,3)$ \\
\hline \multicolumn{3}{|l|}{ Screen Time d } \\
\hline$<4$ hours per day & 396 & $35,7(32,6-39,0)$ \\
\hline$\geq 4$ hours per day & 713 & $64,2(61,0-67,4)$ \\
\hline \multicolumn{3}{|l|}{ Hours of Sleep } \\
\hline$<8$ hours of sleep & 546 & $49,1(45,5-52,6)$ \\
\hline$\geq 8$ hours of sleep & 573 & $50,9(47,3-54,5)$ \\
\hline \multicolumn{3}{|l|}{ Body fat } \\
\hline No excess & 742 & $65,6(36,2-86,5)$ \\
\hline With excess & 390 & $34,4(13,4-63,8)$ \\
\hline
\end{tabular}

$\mathrm{Cl}=$ confidence interval; $\mathrm{A}=$ Minimum salary of $\mathrm{R} \$ 724.00 ; \mathrm{B}=$ physically active at least 60 minutes per day on five or more days of the week; $\mathrm{C}=$ Displacement from home to school by walking or cycling; $D=\Sigma$ of the daily time of Television, Video game and computer. 
The prevalence of adolescents who had excess body fat and, simultaneously, insufficient hours of sleep/ day corresponded to $17.5 \%$ of the sample. Schoolchildren who did not present excess body fat and simultaneously had excessive hours of being awake corresponded to
$31.6 \%$ of the sample. The prevalence of individuals who had excess body fat and slept sufficient hours of sleep per day was $16.8 \%$. Still, the prevalence of adolescents who presented the combination of excess body fat and sufficient hours of sleep per day was 34.1\% (Table 2).

Table 2: Gross prevalence and odds ratio of overweight of schoolchildren by demographic, socioeconomic variables, sedentary behaviour and health perception. Porto Velho, Rondônia, 2013 and 2014.

\begin{tabular}{|c|c|c|c|c|c|c|}
\hline \multirow[b]{2}{*}{ Variables $^{b}$} & \multicolumn{2}{|c|}{$\begin{array}{c}\text { Without excess of GCl } \\
\text { Sleep }<8 \text { hours }\end{array}$} & \multicolumn{2}{|c|}{$\begin{array}{l}\text { With excess of GC/ } \\
\text { Sleep } \geq 8 \text { hours }\end{array}$} & \multicolumn{2}{|c|}{$\begin{array}{l}\text { With excess of GCl } \\
\text { Sleep }<8 \text { hours }\end{array}$} \\
\hline & n (\%) & OR (Cl95\%) & n (\%) & OR $(\mathrm{Cl} 195 \%)^{\mathrm{a}}$ & n (\%) & OR $(\mathrm{Cl} 195 \%)^{\mathrm{a}}$ \\
\hline TOTAL & $350(31,6 \%)$ & $(19,2-47,2)$ & $189(16,8)$ & $(7,2-34,3)$ & $196(17,5)$ & $(7,3-36,3)$ \\
\hline \multicolumn{7}{|l|}{ Sex } \\
\hline Male & $184(36,4)$ & 1,00 & $83(16,2)$ & 1,00 & $78(15,5)$ & 1,00 \\
\hline \multicolumn{6}{|l|}{ age (years) } & $0,96(0,60-1,52)$ \\
\hline $14-15$ & $78(21,9)$ & 1,00 & $78(22,0)$ & 1,00 & $73(20,3)$ & 1,00 \\
\hline $16-17$ & $222(34,9)$ & $2,17(1,41-3,35)$ & $101(15,6)$ & $0,90(0,57-1,41)$ & $107(16,7)$ & $0,99(0,62-1,56)$ \\
\hline $18-19$ & $50(41,7)$ & $2,79(1,45-5,38)$ & $10(8,1)$ & $0,65(0,28-1,52)$ & $16(13,4)$ & $0,89(0,38-2,11)$ \\
\hline \multicolumn{7}{|l|}{$\begin{array}{l}\text { Monthly Family } \\
\text { Income (minimum } \\
\text { wages) }^{\mathrm{a}}\end{array}$} \\
\hline Up to two wages & $62(24,7)$ & 1,00 & $54(21,7)$ & 1,00 & $38(15,1)$ & 1,00 \\
\hline Two to ten wages & $222(35,3)$ & $1,71(1,10-2,65)$ & $98(15,2)$ & $0,80(0,50-1,27)$ & $86(19,3)$ & $1,43(0,86-2,38)$ \\
\hline Above ten wages & $16(17,1)$ & $2,03(0,45-5,46)$ & $8(18,9)$ & $1,27(0,44-3,73)$ & $7(16,5)$ & $0,97(0,28-3,38)$ \\
\hline \multicolumn{7}{|l|}{ Maternal Education } \\
\hline $\begin{array}{l}\text { Up to eight full } \\
\text { years }\end{array}$ & $199(32,1)$ & 1,00 & $110(17,5)$ & 1,00 & $100(16,0)$ & 1,00 \\
\hline Nine years or more & $145(30,2)$ & $1,01(0,69-1,50)$ & $77(15,9)$ & $0,95(0,61-1,46)$ & $96(19,8)$ & \\
\hline \multicolumn{7}{|l|}{$\begin{array}{l}\text { Global Physical } \\
\text { Activity }\end{array}$} \\
\hline $\begin{array}{l}\text { Does not heed the } \\
\text { recommendations }\end{array}$ & $249(29,8)$ & 1,00 & $153(17,9)$ & 1,00 & $143(16,9)$ & 1,00 \\
\hline $\begin{array}{l}\text { Meets } \\
\text { recommendations }\end{array}$ & $94(37,7)$ & $1,19(0,77-1,86)$ & $35(14,1)$ & $0,97(0,56-1,70)$ & $50(20,1)$ & $1,82(1,09-3,01)$ \\
\hline \multicolumn{7}{|l|}{$\begin{array}{l}\text { Physical Activity at } \\
\text { leisure }\end{array}$} \\
\hline Active activities & $180(30,3)$ & 1,00 & $103(17,1)$ & 1,00 & $113(18,8)$ & 1,00 \\
\hline Passive activities & $154(33,0)$ & $1,05(0,71-1,55)$ & $79(16,6)$ & $1,02(0,64-1,63)$ & $73(15,5)$ & $0,93(0,58-1,47)$ \\
\hline \multicolumn{7}{|l|}{$\begin{array}{l}\text { Number of Physical } \\
\text { Education classes }\end{array}$} \\
\hline One class per week & $54(27,3)$ & 1,00 & $40(19,9)$ & 1,00 & $47(23,5)$ & 1,00 \\
\hline $\begin{array}{l}\text { Two lessons per } \\
\text { week }\end{array}$ & $255(34,6)$ & $0,72(0,43-1,19)$ & $117(15,6)$ & $0,61(0,35-1,07)$ & $107(14,3)$ & $0,41(0,24-0,72)$ \\
\hline $\begin{array}{l}\text { Three or more les- } \\
\text { sons per week }\end{array}$ & $16(17,5)$ & $0,40(0,17-0,94)$ & $19(20,6)$ & $0,61(0,26-1,42)$ & $23(24,8)$ & $0,80(0,37-1,72)$ \\
\hline \multicolumn{7}{|l|}{$\begin{array}{l}\text { Participation in } \\
\text { sports team }\end{array}$} \\
\hline At the & $169(31,5)$ & 1,00 & $98(18,1)$ & 1,00 & $92(16,9)$ & 1,00 \\
\hline Yes & $175(31,5)$ & $0,77(0,52-1,13)$ & $91(16,1)$ & $0,77(0,49-1,17)$ & $101(18,1)$ & $0,96(0,61-1,51)$ \\
\hline \multicolumn{7}{|l|}{$\begin{array}{l}\text { Displacement to } \\
\text { school }\end{array}$} \\
\hline Passive & $183(32,6)$ & 1,00 & $102(18,1)$ & 1,00 & $112(19,6)$ & 1,00 \\
\hline Active & $157(29,7)$ & $0,91(0,62-1,33)$ & $85(15,7)$ & $0,85(0,55-1,30)$ & $82(15,4)$ & $0,71(0,45-1,11)$ \\
\hline \multicolumn{7}{|l|}{ TV time } \\
\hline$<2$ hours per day & $187(34,7$ & 1,00 & $79(14,6)$ & 1,00 & $109(20,0)$ & 1,00 \\
\hline
\end{tabular}




\begin{tabular}{|c|c|c|c|c|c|c|}
\hline$\geq 2$ hours per day & $158(28,1)$ & $0,91(0,60-1,38)$ & $110(19,1)$ & $1,42(0,86-2,33)$ & $86(15,3)$ & $0,63(0,39-1,02)$ \\
\hline \multicolumn{7}{|l|}{ PC Time } \\
\hline$<2$ hours per day & $143(28,8)$ & 1,00 & $84(16,9)$ & 1,00 & $88(17,8)$ & 1,00 \\
\hline$\geq 2$ hours per day & $202(33,6)$ & $1,79(1,11-2,89)$ & $104(17,0)$ & $0,84(0,51-1,39)$ & $106(17,3)$ & $1,30(0,72-2,35)$ \\
\hline \multicolumn{7}{|l|}{ VG time } \\
\hline$<2$ hours per day & $293(31,4)$ & 1,00 & $161(17,4)$ & 1,00 & $164(17,1)$ & 1,00 \\
\hline$\geq 2$ hours per day & $53(31,3)$ & $0,81(0,48-1,38)$ & $28(15,5)$ & $0,68(0,36-1,29)$ & $32(18,7)$ & $0,87(0,45-1,25$ \\
\hline \multicolumn{7}{|l|}{ Screen Time } \\
\hline$<4$ hours per day & $131(33,4)$ & 1,00 & $60(15,4$ & 1,00 & $71(17,9)$ & 1,00 \\
\hline$\geq 4$ hours per day & $212(30,1)$ & $0,41(0,25-0,68)$ & $128(17,8$ & $1,14(0,65-1,98)$ & $123(17,4)$ & $0,54(0,29-0,99)$ \\
\hline
\end{tabular}

$\mathrm{Cl}=$ confidence interval; $\mathrm{A}=$ Minimum salary of $\mathrm{R} \$ 724.00 ; \mathrm{B}=$ physically active at least 60 minutes per day on five or more days of the week; $\mathrm{C}=$ Displacement from home to school by walking or cycling; $\mathrm{D}=\Sigma$ of the daily time of Television, Video game and computer.

It was verified that the chances of students simultaneously presenting the characteristics excess body fat and sleeping $<8$ hours/day were higher in the adolescents who met the recommendations regarding the practice of weekly physical activity (OR: 1.82; CI 95\%: 1.09-3.01). Students who attended physical education classes twice a week had lower odds for the combination of excess body fat and sleep $<8$ hours/day (OR: 0.41; CI 95\%: 0.24-0.72). Students who spent more than four hours a day in front of the screen had lower chances for excess body fat and sleep $<8$ hours/day (OR: 0.54; CI 95\%: 0.29-0.99) (Table 2).

The girls (OR: 0.58; CI 95\%: 0.39-0.87), students who participated in three or more physical education

\section{DISCUSSION}

The findings show that approximately one in five schoolchildren presented the combination of excess body fat and insufficient hours of sleep/day. The schoolchildren who fulfilled the recommendations regarding the weekly practice of physical activity were more likely to present concomitant excess body fat and insufficient hours of sleep/day. Students who participated in two physical education classes per week and spent time on screen four or more times a day were less likely to present the combination of excess body fat and insufficient hours of sleep/day.

The combined prevalence of excess body fat and insufficient sleep/day hours in this study was $17.5 \%$. In the study carried out in South Korea, a lower prevalence $(12.3 \%)$ of adolescents with this condition was estimat$\mathrm{ed}^{28}$. Several authors have devoted themselves to studying the relationship of this issue in the health field, mainly due to its outcome, given that insufficient number of hours of sleep/day can lead to losses in the regulation of basal energy metabolism, contributing to an increase in body fat $\mathrm{t}^{10,12}$.

The high prevalence of excess body fat and insufficient sleep/day hours described in this study warrants the need for attention by the health control media, since the combination of these behaviours was strongly associated with cardiometabolic diseases, dyslipidaemia ${ }^{5}$, increased mass decrease in glucose tolerance and a decrease in insulin sensitivity ${ }^{12}$. In the face of the health problems associated with adolescents with both conditions (excess body fat and insufficient number of hours of sleep/day), it is important to propose effective actions aimed at the prevention of this problem, such as the realization of programmes with- classes per week (OR: 0.40; CI 95\%: 0.17-0,94) and those who reported spending four or more hours in front of the screen (OR: 0.41 ; CI 95\%: 0.25-0.68) were less likely to present the combination without excess body fat and sleep $<8$ hours/day. Higher odds for the simultaneous presence of characteristics not having excess body fat and sleeping $<8$ hours per day were verified in schoolchildren aged 16 to 17 years (OR: 2.17; CI 95\%: 1.41-3.35), 18 to 19 years (OR: 2.79; CI 95\%: 1.45-5.38), in those whose families had income of two to ten minimum wages (OR: 1.71 ; CI 95\%: 1.10-2.65), and those who spent a period of more than or equal to two hours using PC (OR: 1.79; CI 95\%: 1.11-2.89).

in the school environment, through lectures, with students and teachers addressing the issue, also informing parents of adolescents about the problems of excess body fat and insufficient number of hours of sleep/day.

Adolescents who simultaneously had excess body fat and slept insufficiently were more likely to meet the recommended levels of overall physical activity. Similar results were observed in schoolchildren in the United States, where those who reached higher levels of physical activity reported fewer hours of sleep ${ }^{11}$. One of the possible causes of these effects is that adolescents are increasingly involved in extracurricular activities (academic, social and sports activities) and these are directly associated with a decrease in the number of hours of sleep per day ${ }^{9}$. In addition, the decrease of hours of sleep a day contributes to an increase in body fat ${ }^{10,12}$ through hormonal changes and consequently an increase in appetite and a greater intake of calories ${ }^{12}$.

Adolescents who participated in two physical education classes per week were less likely to present excess body fat and insufficient hours of sleep/day. In addition, adolescents who participated in one physical education class per week were more likely to present insufficient number of hours of sleep per day without excess body fat. The findings of the present study reflect that the participation in physical education classes brought benefits to the health of the adolescents when it comes to the maintenance of the corporal weight, but did not have an association with the sufficient quantity of hours of sleep/day. The results found were in agreement with previous studies that 
described the school environment as a potential for the development of physical activity practice and awareness of health aspects ${ }^{29,30}$. The authors emphasized that physical education classes, even if increased in number, will only bring beneficial effects to the health of adolescents if they are of quality and have continuous and sequential objectives $^{29,30}$.

In the present study, girls were less likely to present excess body fat while sleeping insufficient hours of sleep per day. The finding corroborates results found by Hoefelmann et al. ${ }^{9}$, in which girls were less likely to have insufficient hours of sleep/day. However, she disagrees with research by Garaulet et al. ${ }^{10}$ in which girls were more likely to have insufficient hours of sleep/day. Regarding excess body fat, the result found in the present study agrees with the findings of Adami and Vasconcelos ${ }^{26}$ in which there was also a lower chance of excess body fat in girls. However, a study by Silva et al. ${ }^{4}$ found that girls were more likely to present excess body fat. With the results found, it is observed that the associations between being of a given sex and having or not being overweight and/or sleeping inadequately are not yet conclusive.

Those adolescents who had a higher chance of having the condition without excess fat and insufficient hours of sleep/day were the older ones. The finding agrees with that found in a study by Hoefelmann et al. ${ }^{9}$ in which insufficient sleep hours were related to being older. When it comes to excess body fat, it is in agreement with results found by Salvador et al. ${ }^{3}$, in which older adolescents were less likely to present excess body fat. The decrease in the number of hours of sleep with advancing age in older adolescents is well established in the literature ${ }^{6,9}$, in which the plausibility of such a relationship would be that concomitant with the increase of the adolescents' age increases responsibilities and social commitments resulting in fewer hours of sleep and more tasks ${ }^{6,9}$.

Adolescents who had a better chance of simultaneously presenting the combination without excess body fat and insufficient hours of sleep/day came from families with a monthly family income of two to 10 minimum wages. This finding corroborates the findings of Hoefelmann et al. ${ }^{9}$, in which less than eight hours of sleep was related to the average income. Regarding excess body fat, the findings disagree with that found in a study by Salvador et al. ${ }^{3}$, in which the prevalence of excess body fat was associated with mean income. Insufficient sleep hours in middle-income adolescents could be explained by the fact that they have greater access to electronic devices such as computers, as compared to low-income adolescents ${ }^{2}$. The longer time of use of computers and, consequently, longer time in connection with social networks, leads to a reduction in the number of hours of sleep ${ }^{6}$.

The adolescents who were more likely to present the combination without excess body fat and insufficient sleep/day hours were those who spent time equal to or greater than two hours on a PC. A similar result was found in a study by Fotti et al. ${ }^{6}$, in which adolescents who spent longer hours in front of the PC were less likely to have insufficient hours of sleep ( $>8$ hours). The relationship between excessive body time with excess body fat and insufficient hours of sleep/day is established in the liter- ature $^{6,14,15}$. However, when investigating PC time and the combination of conditions (excess body fat and hours of sleep), it can be observed that the cut-off point adopted for such classification in relation to excessive use of PC $(\geq 2$ hours) only identified alterations in relation to the number of hours of sleep and not in relation to body fat ${ }^{6}$.

The adolescents who had a higher chance of concomitantly presenting the condition without excess body fat and insufficient sleep/day hours were also those who spent a total screen time of four hours or more per day. Still, schoolchildren who spent four hours or more a day in front of electronic devices also had the characteristic of having both excess body fat and insufficient sleep/day. These results demonstrated that regardless of body fat, sleeping insufficient number of hours of sleep/day was associated with longer screen time. A possible justification for the results of this research in relation to screen time would be that the use of electronic equipment (PC, VG, TV) in the night period increases the psychophysiological excitation, since the exposure to bright light coming from electronic devices can delay the circadian cycle and contribute to worsening quality and number of hours of sleep ${ }^{15}$.

As a limitation of this study, the insufficient statistical power of the sample to test some associations (sex, school dislocation and TV time) must be highlighted, and future studies with a greater number of participants are necessary in order to guarantee power to extrapolate the data to the population of interest.

The present study presents an important contribution to the area of health, since it identified factors predictive of the simultaneity of behaviours in adolescents. These results are relevant because they represent risk factors for the diseases associated with said combination of behaviours. Moreover, the use of sexual maturation and sleep quality as control variables of the adjusted model aimed at minimizing inaccurate results in relation to behaviours related to excess body fat and insufficient sleep hours can be considered as a strong point of this research.

It can be concluded that approximately one-fifth of the adolescents presented both excess body fat and insufficient sleep. These adolescents were those who met the recommendations regarding the practice of weekly physical activity. Schoolchildren who performed two physical education classes per week and those who spent four or more hours in front of the screen had a lower chance of having such a combination of behaviours.

\section{Authors' contributions}

TRL participated in the elaboration, analysis, interpretation of the results and writing of the manuscript. GRS and JACC performed data collection and assisted in the discussion of the manuscript. DASS assisted in the elaboration, statistical analysis and revision of the manuscript.

\section{Acknowledgement}

The authors thank the National Council for Scientific and Technological Development (CNPq) and Coordination for the Improvement of Higher Education Personnel (CAPES) for the subsidies provided for this research. 


\section{REFERENCES}

1. Wolrd Health Organization (WHO). Obesity and overweight. Geneva: WHO; 2016.

2. Instituto Brasileiro de Geografia e Estatística (IBGE). Pesquisa de orçamentos familiares - POF 2008-2009. Despesas, rendimentos e condições de vida. Rio de Janeiro: IBGE; 2010.

3. Salvador CCZ, Kitoko PM, Gambardella AMD. Estado nutricional de crianças e adolescentes: fatores associados ao excesso de peso e acúmulo de gordura. J Hum Growth Dev. 2014;24(3):313-9. DOI: http://dx.doi.org/10.7322/jhdg.88969

4. Silva KS, Nahas MV, Hoefelmann LP, Lopes AS, Oliveira ES. Associações entre atividade física, índice de massa corporal e comportamentos sedentários em adolescentes. Rev Bras Epidemiol. 2008;11(1):159-68. DOI: http://dx.doi.org/10.1590/s1415-790X2008000100015

5. Rizzo A, Goldberg T, Silva CC, Kurokawa CS, Nunes H, Corrente JE. Metabolic syndrome risk factors in overweight, obese, and extremely obese Brazilian adolescents. Nutr J. 2013;12:19. DOI: http://dx.doi.org/10.1186/1475-2891-12-19

6. Foti KE, Eaton DK, Lowry R, McKnight-Ely LR. Sufficient sleep, physical activity, and sedentary behaviors. Am J Prev Med. 2011;41(6):596-602. DOI: http://dx.doi.org/10.1016/j.amepre.2011.08.009

7. Drake C, Kryger M, Phillips B. Summary of findings. 2005 sleep in America poll. National Sleep Foundation. 2005.

8. Matricciani L, Olds T, Petkov J. In search of lost sleep: secular trends in the sleep time of school-aged children and adolescents. Sleep Med Rev. 2012;16(3):203-11. DOI: http://dx.doi.org/10.1016/j.smrv.2011.03.005

9. Hoefelmann LP, Lopes AS, Silva KS, Moritz P, Nahas MV. Sociodemographic factors associated with sleep quality and sleep duration in adolescents from Santa Catarina, Brazil: what changed between 2001 and 2011? Sleep Med. 2013;14(10):1017-23. DOI: http://dx.doi.org/10.1016/j.sleep.2013.05.015

10. Garaulet M, Ortega F, Ruiz J, Rey-Lopez J, Beghin L, Manios Y, et al. Short sleep duration is associated with increased obesity markers in European adolescents: effect of physical activity and dietary habits. The HELENA study. Int J Obes (Lond). 2011;35(10):1308-17. DOI: http://dx.doi.org/10.1038/ijo.2011.149

11. Pesonen AK, Sjöstén NM, Matthews KA, Heinonen K, Martikainen S, Kajantie E, et al. Temporal associations between daytime physical activity and sleep in children. PLoS One. 2011;6(8):e22958. DOI: http://dx.doi.org/10.1371/journal.pone.0022958

12. Leproult R, Van Cauter E. Role of sleep and sleep loss in hormonal release and metabolism. Endocr Dev. 2010;17:11-21. DOI: http://dx.doi.org/10.1159/000262524

13. Sena ASS, Cardoso AS, Carvalho DF, Medeiros JL, Coutinho GF, Albuquerque FCL, et al. Sonolência diurna excessiva e fatores de risco cardiometabólicos em crianças e adolescentes com excesso de peso. J Hum Growth Dev. 2013;23(1):24-30. DOI: http://dx.doi.org/10.7322/jhgd.50387

14. Tremblay MS, LeBlanc AG, Kho ME, Saunders TJ, Larouche R, Colley RC, et al. Systematic review of sedentary behaviour and health indicators in school-aged children and youth. Int J Behav Nutr Phys Act. 2011;8:98. DOI: http://dx.doi.org/10.1186/1479-5868-8-98

15. Cain N, Gradisar M. Electronic media use and sleep in school-aged children and adolescents: A review. Sleep Med. 2010;11(8):735-42. DOI: http://dx.doi.org/10.1016/j.sleep.2010.02.006

16. Instituto de Pesquisa Econômica Aplicada (IPEA). O Índice de desenvolvimento humano municipal brasileiro. Brasilia: IPEA; 2013.

17. Phillips C. Sample size and power: What Is enough? Seminars Orthodontics. 2002; 8(2):67-76. DOI: http://dx.doi.org/10.1053/sodo.2002.32074

18. Onis M, Onyango AW, Borghi E, Siyam A, Nishida C, Siekmann J. Development of a WHO growth reference for school-aged children and adolescents. Bull World Health Organ. 2007;85(9):660-7. DOI: http://dx.doi.org/10.1590/S0042-96862007000900010

19. Fórum nacional de Educação (FNE). Educação Brasileira: indicadores e desafios. Brasilia: FNE; 2013.

20. Instituto Brasileiro de Geografia e Estatistica (IBGE). Metodologia do censo demográfico 2010. Rio de Janeiro: IBGE; 2013.

21. Guedes DP, Lopes CC. Validação da versão brasileira do Youth Risk Behavior Survey 2007. Rev Saúde Pública. 2010;44(5):840-50. DOI: http://dx.doi.org/10.1590/S0034-89102010000500009

22. Strong WB, Malina RM, Blimkie CJ, Daniels SR, Dishman RK, Gutin B, et al. Evidence based physical activity for school-age youth. J Pediatr. 2005;146(6):732-7. DOI: http://dx.doi.org/10.1016/j.jpeds.2005.01.055

23. Wijndaele K, Brage S, Besson H, Khaw KT, Sharp SJ, Luben R, et al. Television viewing time independently predicts all-cause and cardiovascular mortality: the EPIC Norfolk study. Int J Epidemiol. 2011;40(1):150-9. DOI: http://dx.doi.org/10.1093/ije/dyq105

24. Martins MO, Cavalcante VLF, Holanda GS, Oliveira CG, Maia FES, Meneses Júnior JR, et al. Associação entre comportamento sedentário e fatores psicossociais e ambientais em adolescentes da região nordeste do Brasil. Rev Bras Ativ Fís Saúde. 2012;17(2):143-50. DOI: http://dx.doi.org/10.12820/rbafs.v.17n2p143-150

25. Marshall WA, Tanner JM. Variations in pattern of pubertal changes in girls. Arch Dis Child. 1969;44(235):291-303.

26. Adami F, Vasconcelos FAG. Obesidade e maturação sexual precoce em escolares de Florianópolis - SC. Rev 
Bras Epidemiol. 2008;11(4):549-60. DOI: http://dx.doi.org/10.1590/S1415-790X2008000400004

27. Fletcher J. Clinical Epidemiology Notes: What is heterogeneity and is it important? BMJ. 2007;334(7584):94-6. DOI: https://doi.org/10.1136/bmj.39057.406644.68

28. Park S. Association between short sleep duration and obesity among South Korean adolescents. West J Nurs Res. 2011;33(2):207-23. DOI: https://doi.org/10.1177/0193945910371317

29. Costa FF, Garcia LMT, Nahas MV. A Educação Física no Brasil em transição: perspectivas para a promoção da atividade física. Rev Bras Ativ Fís Saúde. 2012;17(1):14-21.

30. Ribeiro EH, Florindo AA. Efeitos de um programa de intervenção no nível de atividade física de adolescentes de escolas públicas de uma região de baixo nível socioeconômico: descrição dos métodos utilizados. Rev Bras Ativ Fís Saúde. 2010;15(1):28-34. DOI: http://dx.doi.org/10.12820/rbafs.v.15n1p28-34

\section{Resumo}

Introdução: O aumento do excesso de gordura corporal e a diminuição do número de horas de sono/ dia são agravos à saúde que atingem a população pediátrica.

Objetivo: Estimar a prevalência combinada de excesso de peso e horas de sono/dia insuficientes em adolescentes, e verificar a associação com características sociodemográficas, de atividade física e comportamento sedentário.

Método: Estudo transversal de base escolar, realizado com 1.132 participantes de 14 a 19 anos de idade, em São José, Brasil. A gordura corporal foi avaliada pelo Índice de Massa Corporal (IMC) e classificado por meio do escore-Z, enquanto o total de horas de sono/dia foi relatado pelos adolescentes. Os dados sociodemográficos, de atividade física e comportamento sedentário foram levantados por questionário autopreenchível.

Resultados: A prevalência simultânea de excesso de peso e horas de sono/dia insuficientes foi de $17,5 \%$. Os fatores associados a esta condição foram atender as recomendações de prática de atividade física semanal, participar da aula de educação física duas vezes/semana e período maior/igual a quatro horas/dia em frente a tela.

Conclusão: Orientações no ambiente escolar em relação aos problemas à saúde acarretados pelo excesso de peso e pela quantidade de horas de sono insuficientes podem se fazer presentes quando recomendações sobre atividade física e comportamento sedentário forem dadas aos estudantes

Palavras-chave: obesidade, sobrepeso, indice de massa corporal, epidemiologia, saúde do adolescente, atividade motora, estudos transversais

${ }^{0}$ The authors (2017), this article is distributed under the terms of the Creative Commons Attribution 4.0 International License (http://creativecommons.org/licenses/by/4.0/), which permits unrestricted use, distribution, and reproduction in any medium, provided you give appropriate credit to the original author(s) and the source, provide a link to the Creative Commons license, and indicate if changes were made. The Creative Commons Public Domain Dedication waiver (http://creativecommons.org/ publicdomain/zero/1.0/) applies to the data made available in this article, unless otherwise stated. 